\title{
Isolation and characterization of Beauveria and Metarhizium spp. from walnut fields and their pathogenicity against the codling moth, Cydia pomonella (L.) (Lepidoptera: Tortricidae)
}

\author{
Songül Gürlek ${ }^{1}$, Ali Sevim${ }^{1}$ Fikriye Milletli Sezgin ${ }^{2}$ and Elif Sevim ${ }^{1 *}$ (D)
}

\begin{abstract}
Entomopathogenic fungi (EPFs) play an important role for regulating insect pest populations, as they exist in many different ecosystems. Within these fungi, Beauveria and Metarhizium spp. genera include species that are the most commercially important. The aim of this study was to determine the diversity and distribution of Beauveria and Metarhizium spp. in walnut fields of Kırşehir, Turkey, and to evaluate their pathogenicity against Cydia pomonella (L.) (Lepidoptera: Tortricidae). To perform this, 90 soil samples were collected from walnut fields where Beauveria and Metarhizium spp. were isolated from these soils, using selective media. The isolated 40 fungi were characterized based on their morphological and molecular characteristics including Bloc and $\beta$-tubulin gene sequences. Also, eight selected fungi were tested against C. pomonella larvae under laboratory conditions. The fungal isolates were identified as Beauveria pseudobassiana (15), B. bassiana (12), Metarhizium robertsii (11), and M. brunneum (13). M. brunneum ELA-38 caused $83 \%$ mortality within 2 weeks after application of $1 \times 10^{8}$ conidia/ml. Consequently, Beauveria and Metarhizium spp. are the common component of the soils collected from walnut fields and some of fungi obtained from this work might be beneficial in the future biological control programs of $C$. pomonella.
\end{abstract}

Keywords: Entomopathogenic fungi, Pathogenicity, Walnut, Codling moth, Cydia pomonella

\section{Background}

Entomopathogenic fungi (EPFs) cause lethal infections in their host, and they are the natural regulator of many insect pests including those living in soil by epizootics (Goettel et al. 2005). These microorganisms have attracted remarkable attention for their usage in biological control programs of insect pests in both agriculture and forestry as environmentally safe agents (Lacey et al. 2015; Strasser et al. 2010). Among these fungi, Beauveria bassiana (Balsamo) Vuillemin and Metarhizium anisopliae (Metschn.) Sorokin are the most studied fungi in terms of commercial production (Goettel et al. 2005; Meyling and Eilenberg 2007). In the majority of the EPFs, the infection

\footnotetext{
* Correspondence: esevim@ahievran.edu.tr

${ }^{1}$ Ahi Evran University, Faculty of Engineering and Architecture, Genetic and Bioengineering, 40100 Kırşehir, Turkey

Full list of author information is available at the end of the article
}

process begins with the attachment of conidial spores on the external body surface of insects (cuticle).

Soil is an important reservoir for EPFs, and these soil fungi have a great importance in terms of biological control. Many EPFs such as B. bassiana, M. anisopliae, and Paecilomyces spp. spend a significant period of their life cycle in soil (Jackson et al. 2000). The local isolates have many advantages in comparison to exotic isolates because they may have ecological compatibility with the pest species. This reduces the effect of the used agents against non-target organisms (Gulsar Banu et al. 2004).

The codling moth, Cydia pomonella L. (Lepidoptera: Tortricidae), is an important pest of many agricultural fruits such as apple, quince, pear, peach, and walnut worldwide. It may cause $100 \%$ crop losses when it is not controlled (Mamay and Yanık 2013). In Turkey, the control of this pest depends upon chemical insecticides 
(Republic of Turkey, Ministry of Agriculture and Welfare 2010). The use of these chemical insecticides has harmful effects on environment and humans. Moreover, pest species in agriculture and forestry gain resistance to such chemical insecticides used (Mota-Sanchez et al. 2008). Besides, some biological control agents such as the parasitoids (Liotryphon caudatus, Bassus ruwpes, and Mastrus ridibundus) and the entomopathogens (C. pomonella granulosis virus, Bacillus thuringiensis, Beauveria bassiana, Nosema carpocapsae, and Steinerma sp.) have showed some potential (Mills 2005; Zimmermann et al. 2013).

EPFs can be adapted to their environmental conditions such as certain climatic conditions and habitat types (Sevim et al. 2012). Therefore, it is important to isolate and identify local fungal strains for controlling insect pests in related areas.

The present study aimed to isolate and characterize indigenous soil-borne EPFs from soil samples collected from walnut fields near Kirşehir, Turkey. In addition, the pathogenicity of the isolated fungi against $C$. pomonella larvae under laboratory conditions was evaluated.

\section{Methods}

\section{Sampling}

Ninety soil samples were collected from a depth of about $20 \mathrm{~cm}$. Before collection, the surface layer of soil was removed. A total of five soil samples was taken from each collection site and placed in a plastic bag and transported to the laboratory. The five collected soil samples of each site were placed together in a plastic bag and mixed completely. Small stones and some rough parts were removed (Sevim et al. 2010a). Finally, 1-g soil sample was used to isolate EPFs.

\section{Isolation of Beauveria and Metarhizium spp.}

One gram of a given soil sample and $10 \mathrm{ml}$ of the sterilized distilled water were mixed in 15-ml test tubes, which were vortexed for $10 \mathrm{~min}$ to obtain homogenous solution. Then, a serial dilution from $10^{-1}$ to $10^{-7}$ for each soil sample was prepared to isolate a single colony of fungi. Two hundred fifty microliters of the obtained soil extracts from each tube was spread on selective medium (SDA (Sabouraud Dextrose Agar) containing $0.2 \mu \mathrm{g} / \mathrm{ml}$ dodine ( $\mathrm{N}$-dodecylguanidine monoacetate), $100 \mu \mathrm{g} / \mathrm{ml}$ chloramphenicol, and $50 \mu \mathrm{g} / \mathrm{ml}$ streptomycin sulphate) and incubated at $28{ }^{\circ} \mathrm{C}$ for 2 weeks (Goettel and Inglis 1997). At the end of the incubation period, growing single colonies were transferred on other SDA plates to get pure cultures. One hundred microliters of conidial suspension $\left(1 \times 10^{5}\right.$ conidia/ml $)$ for each fungal isolate was plated on PDAY ( $1 \%$ yeast extract and potato dextrose agar) and incubated at $28{ }^{\circ} \mathrm{C}$ for 1 week to select colonies derived from a single colony. The selected colonies from a single colony were transferred on another PDAY for further investigation. All purified fungal isolates were stored in $15 \%$ glycerol at $-20{ }^{\circ} \mathrm{C}$.

\section{Identification of fungal isolates}

Firstly, fungal isolates were morphologically characterized based on some fungal structures obtained from monosporic pure cultures. Colony morphologies, conidia, and conidiogenous cell shapes were used for initial characterization. All isolates were identified based on the identification key of Humber (1997). Morphological identification of the isolated fungi was confirmed by molecular characterization, using gene sequences of the nuclear intergenic region (bloc) and beta-tubulin $(B t)$. Genomic DNAs were extracted from monosporic fungal cultures, using the microbial DNA isolation kit (MO-BIO, Carlsbad, CA, USA) according to the manufacturer's recommendations. For Beauveria isolates, approximately 1500-bp segments of bloc gene region was amplified by the primer pairs of B5.1F (5'-CGACCCGGCCAACT ACTTTGA-3') and B3.1R (5'-GTCTTCCAGTACCA CTACGCC-3') as described in the paper of Rehner et al. (2006). PCR conditions were adapted according to Rehner et al. (2006). For Metarhizium isolates, an approximately 1300-bp segments of $B t$ gene region were amplified by PCR, using the primer pairs of $\mathrm{T} 15^{\prime}$-AACATGCGT GAGATTGTAAGT-3') and T22 (5'-TCTGGATGT TGTTGGGAATCC-3') based on O'Donnell and Cigelnik (1997). PCR amplifications for Bt gene region were performed in a total volume of $50 \mu \mathrm{l}$, which included $5 \mu \mathrm{l}$ Taq DNA polymerase reaction buffer, $3 \mu \mathrm{l} \mathrm{MgCl} 2,1.5 \mu \mathrm{l}$ $10 \mathrm{pmol}$ of each primers, $1.5 \mu \mathrm{l} 10 \mathrm{mM}$ dNTP mix, $1 \mu \mathrm{l}$ $5 \mathrm{U} / \mu \mathrm{l}$ of Taq DNA polymerase, $1 \mu \mathrm{l}$ genomic DNA, and $35.5 \mu \mathrm{l} \mathrm{d} \mathrm{H}_{2} \mathrm{O}$. Reactions were first incubated for $5 \mathrm{~min}$ at $95{ }^{\circ} \mathrm{C}$, and then, 35 cycles were performed as follows: $1 \mathrm{~min}$ at $94{ }^{\circ} \mathrm{C}, 1 \mathrm{~min}$ at the annealing temperature of $55^{\circ}$ $\mathrm{C}$, and $2 \mathrm{~min}$ at $72{ }^{\circ} \mathrm{C}$. Reactions were then incubated at $72{ }^{\circ} \mathrm{C}$ for another $5 \mathrm{~min}$.

After performing all amplifications, PCR products were separated on $1.0 \%$ agarose gel and stained with ethidium bromide. The amplified PCR products were viewed under UV light to see correct amplification. Finally, PCR products were sent to the MACROGEN for sequencing. The sequencing process was performed by amplification primers. The obtained sequences were used to carry out phylogenetic analysis.

For Beauveria isolates, the isolated fungi were compared to the known Beauveria species, using bloc sequences according to Rehner et al. (2011) to confirm correct identification. For Metarhizium isolates, the isolated fungi were compared to the fungal isolates and species used in the study of Bischoff et al. (2009) using $B t$ sequences. 


\section{Bioassay experiment}

For bioassay experiment, eight EPFs were used in laboratory bioassay experiment to determine their pathogenicity against C. pomonella larvae. All isolates were initially plated on PDAY, using the conidial concentration of $1 \times 10^{6}$ conidia/ml to obtain the monosporic fungal cultures and then incubated at $28^{\circ} \mathrm{C}$ for 1 week. A single colony derived from a single spore for each isolate was transferred to another PDAY agar and incubated at $28{ }^{\circ} \mathrm{C}$ for 3 weeks. Conidial suspensions were obtained by adding $10 \mathrm{ml}$ of $0.01 \%$ Tween 80 as a wetting agent to each Petri dish and gently scraping the surface of the cultures with a sterile cell scraper. After that, conidial suspensions were filtered through two layers of sterile cheesecloth into a 15-ml test plastic test tube to remove rough parts of medium and mycelia. Conidia were counted using an improved Neubauer hemocytometer. Aqueous suspensions applied in bioassays were prepared by dilution at concentration of $1 \times 10^{8}$ conidia/ml. Conidial viability was determined by spreading $100 \mu \mathrm{l}$ of a $1 \times 10^{6}$ conidia/ml suspension onto the surface of PDAY. After incubation at $28{ }^{\circ} \mathrm{C}$ for $24 \mathrm{~h}$, the numbers of viable and non-viable conidia were counted under a microscope. Conidia were considered to have germinated if the germ tube was longer than the diameter of the conidium. Isolates with a viability of above $95 \%$ were used for bioassay experiments (Sevim et al. 2010b).

A conidial concentration of $1 \times 10^{8}$ conidia $/ \mathrm{ml}$ was used to determine the pathogenicity of all tested isolates against C. pomonella larvae. For the bioassay experiment, the healthy C. pomonella larvae were obtained from laboratory culture at Ahi Evran University, Genetic Bioengineering, and Microbiology Laboratory. Healthy larvae were randomly selected and used for the bioassay. For each isolate, 10 larvae were directly immersed in the conidial suspension for $5 \mathrm{~s}$. Another 10 larvae were immersed in 0.01\% Tween 80 solutions as a control group. The treated and control larvae were separately placed into plastic boxes $(20 \mathrm{~mm})$ containing freshly prepared artificial diet with ventilated lids to permit airflow. Ten larvae were used for each replicate, and all experiments were repeated three times on different occasions. Finally, all boxes were incubated for a period of 2 weeks at $25{ }^{\circ} \mathrm{C}$ in darkness. The test larvae were checked daily to record mortality rate. At the end of the incubation period, all dead larvae were surface sterilized with $2 \%$ sodium hypochlorite solution for $2 \mathrm{~min}$, followed by $70 \%$ ethanol for $2 \mathrm{~min}$, and washed two times in sterile distilled water for $30 \mathrm{~s}$. After that, they were placed into the moisture chamber to stimulate fungal sporulation outside the cadaver to confirm infection by the tested fungi.

\section{Data analysis}

The obtained sequences of complimentary strands were edited and aligned with Clustal W contained within
Bioedit version 7.1.3.0 (Hall 1990; Thompson et al. 1994). The partial sequences of bloc gene regions from Beauveria isolates used in this study and reference isolates from the study of Rehner et al. (2011) were combined, using Bioedit. For Metarhizium isolates, Bt gene sequences from this study and the study of Bischoff et al. (2009) were combined and used for phylogenetic analysis. Phylogenetic analyses, using the maximum likelihood (ML) method, were performed by PHYML software packed in SeaView version 4 by selecting the general time-reversible (GTR)-based substitution matrix and gamma distribution (Guindon et al. 2010; Gout et al. 2010). The reliability of the dendrogram was tested by bootstrap analysis with 1000 pseudoreplicates, using SeaView version 4. Mortality data were corrected according to Abbott's formula (Abbott 1925). Differences between the fungal isolates and the control group, with respect to mortality and mycosis, were determined by analysis of variance (ANOVA) and subsequently by Dunnett's one-tailed $t$ test. Differences among the fungal isolates with respect to mortality rates and mycosis were determined by ANOVA and subsequently by LSD multiple comparison test. All analyses were performed by using SPSS 16.0 statistical software.

\section{GenBank accession numbers}

The DNA sequences obtained from this study were deposited in NCBI GenBank database. For Beauveria isolates (ELA-1, ELA-2, ELA-4, ELA-5, ELA-6, ELA-7, ELA-8, ELA-9, ELA-11, ELA-13, ELA-14, ELA-15, ELA-16, ELA-18, ELA-24, ELA-25, ELA-26, ELA-27, ELA-28, ELA-29, ELA-30, ELA-31, ELA-32, ELA-35, ELA-36, ELA-37, ELA-40, ELA-41 and ELA-42), accession numbers are from MH181833 to MH181861. For Metarhizium isolates (ELA-3, ELA-10, ELA-12, ELA-17, ELA-19, ELA-20, ELA-21, ELA-22, ELA-23, ELA-33, ELA-34, ELA-38 and ELA-39), accession numbers are from MH181862 to MH181874.

\section{Results and discussion}

Forty fungal isolates were obtained from 90 soil samples, using dodine-based selective media. More than one fungal isolate was obtained from some soil samples. $32.2 \%$ of the soil samples was positive in respect to the presence of EPFs. Isolated fungal strains were identified as Beauveria pseudobassiana (15), B. bassiana (12), Metarhizium robertsii (11), and M. brunneum (13) based on their morphological and molecular characterizations. Species identification of the fungal isolates was confirmed by phylogenetic analysis (Figs. 1 and 2).

Eight selected fungal isolates were tested against $C$. pomonella larvae under laboratory conditions. All isolates caused different mortality rates $(F=29.662, \mathrm{df}=8$, $p<0.05)$ and mycosis values $(F=16.734, \mathrm{df}=8, p<0.05)$ 


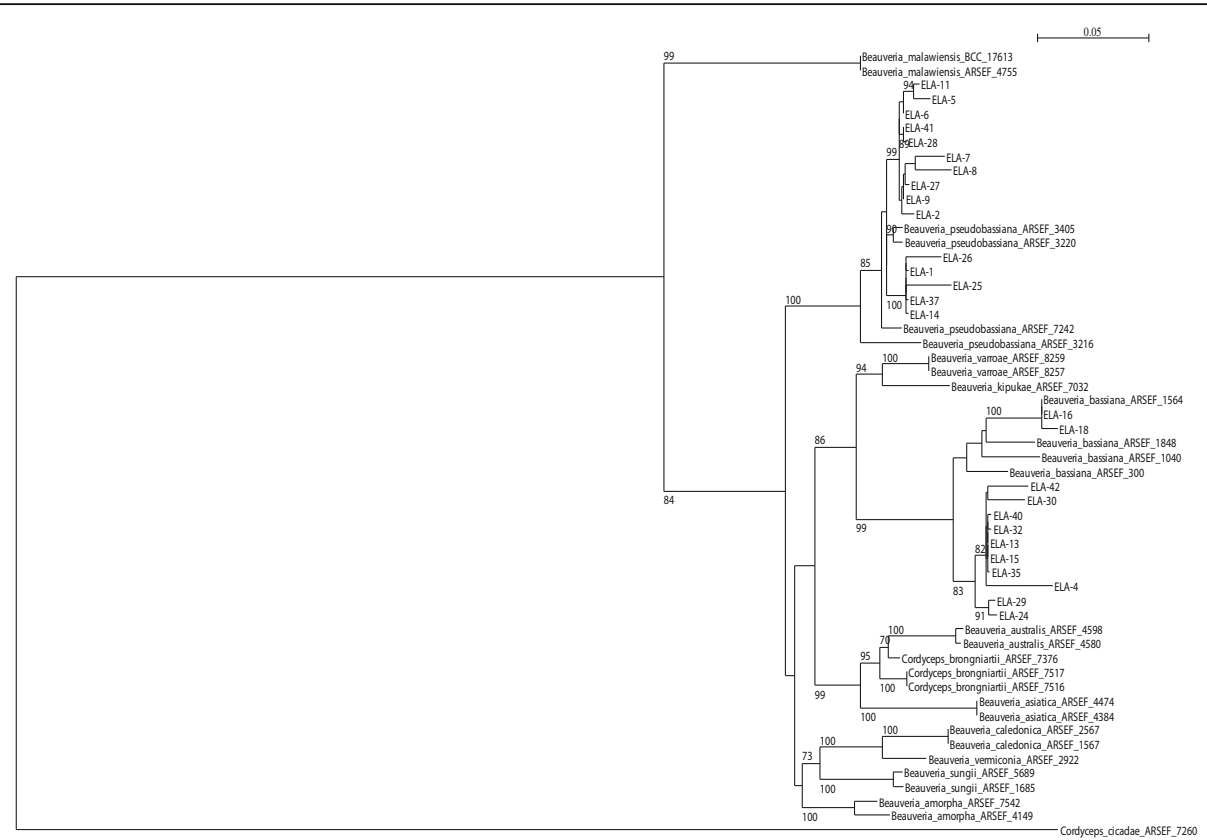

Fig. 1 Phylogenetic tree derived from maximum likelihood (ML) analysis of bloc gene sequences belonging to the Beauveria isolates and their closely related species indicated in the study of Rehner et al. (2011). Bootstrap values based on 1000 replicates were indicated above nodes. Bootstrap values $C \geq 70$ are labeled. The scale on the top of the phylogram indicates the degree of dissimilarity

in comparison to control groups. All isolates caused different mortality rates in comparison to each other $(F=19.571, \mathrm{df}=7, p<0.05)$. The highest mortality rate (83\%) was obtained by M. brunneum ELA-38 with $(F=19.571$, $\mathrm{df}=7, p<0.05)$ (Fig. 3). In addition, all isolates caused different mycosis values in comparison to each other $(F=11.214, \mathrm{df}=7, p<0.05)$ and the highest mycosis (80\%) was obtained by M. brunneum ELA-38. Other mortality rates and mycosis values ranged from 23 to $70 \%$ and from 16 to $70 \%$, respectively (Fig. 3).

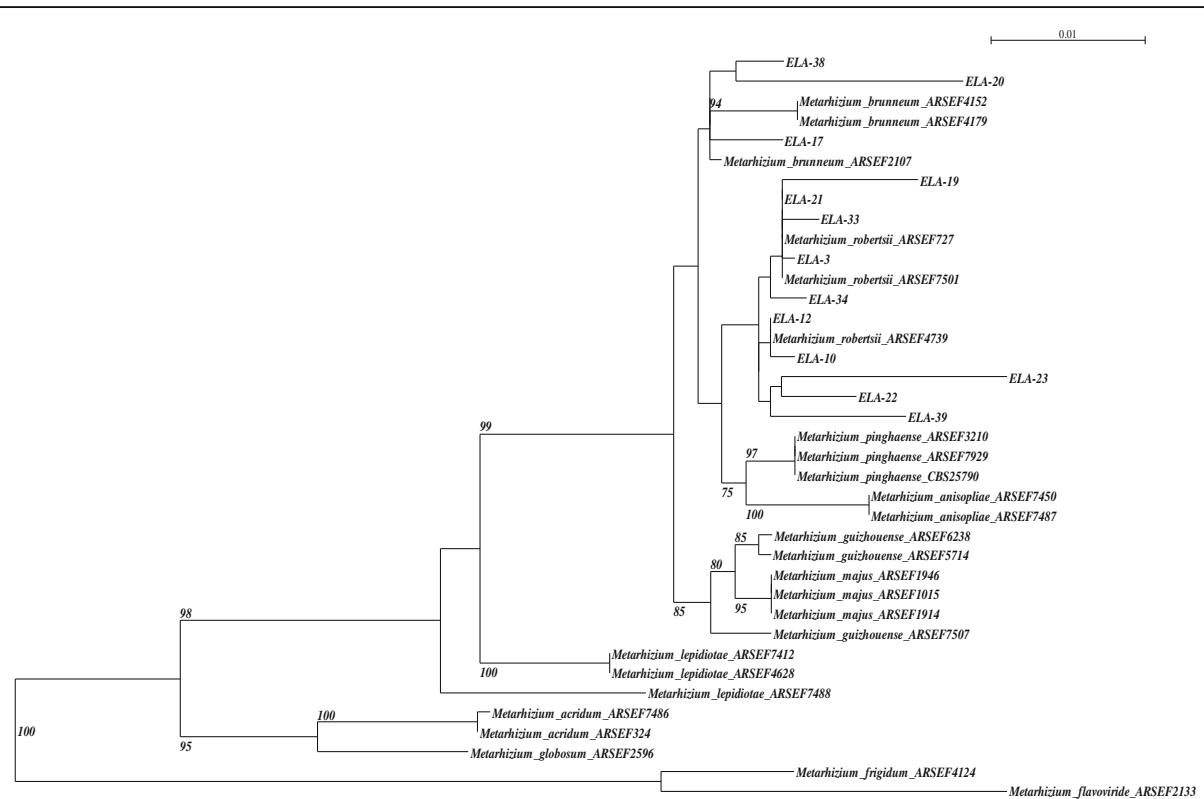

Fig. 2 Phylogenetic tree derived from maximum likelihood (ML) analysis of $\beta$-tubulin gene sequences belonging to the Metarhizium isolates and their closely related species indicated in the study of Bischoff et al. (2009). Bootstrap values based on 1000 replicates were indicated above nodes. Bootstrap values $C \geq 70$ are labeled. The scale on the top of the phylogram indicates the degree of dissimilarity 


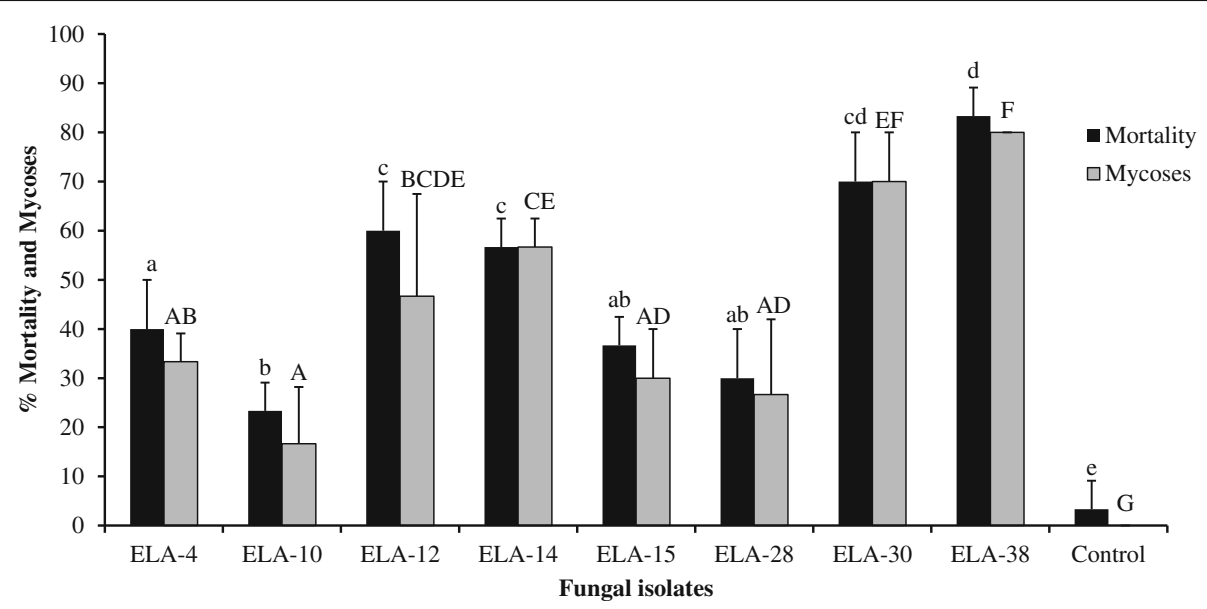

Fig. 3 Virulence of eight selected fungal isolates using the conidial concentration of $1 \times 10^{8}$ conidia/ml against C. pomonella larvae within 2 weeks after application. Mortality data were corrected according to Abbott's formula (Abbott, 1925). Bars indicate standard deviations. Different lowercase and uppercase letters represent statistically significant differences among larval mortalities and mycosis values, respectively. ELA-4, 15, 30 Beauveria bassiana; ELA-14 and 28 B. pseudobassiana; ELA-10 and 12 Metarhizium robertsii; ELA-38 M. brunneum

EPFs have been used to control insect pests, and they play an important role in the regulation of insect populations in nature. Until now, approximately 170 commercial products have been developed based on different EPF species (Lovett and St Leger 2017). Considering the abundance and diversity of EPFs in soils of temperate regions, it is possible to confirm that Beauveria bassiana (Balsamo) Vuillemin and Metarhizium anisopliae (Metsch.) Sorokin are the most abundant species (Perez-Gonzales et al. 2014).

Many studies have showed the isolation and infectivity of EPFs, including B. bassiana and M. anisopliae, against larvae of economic pests (Lacey and Unruh 2005; Zimmermann et al. 2013). It has been reported that application of biological commercial insecticide Boverin that was produced, using $B$. bassiana, successfully reduced populations of C. pomonella (Gardner and McCoy 1992). Abaajeh and Nchu (2015) isolated many EPFs from soil samples, using C. pomonella larvae as insect bait technique and tested some of these fungi against the pest's larvae. Two $M$. robertsii strains (MTL151 and GW461) caused (85\%) larval mortality. Solis-Soto et al. (2006) evaluated the efficacy of $B$. bassiana BbPM blastospores against $C$. pomonella larvae and found that the used strain caused (96\%) larval mortality, within $72 \mathrm{~h}$ after exposure, using the $1.2 \times 10^{9}$ spores $/ \mathrm{ml}$. Garcia-Gutierrez et al. (2004) tested B. bassiana BbP1 and two commercials, $B$. bassiana- and $M$. anisopliae-based formulations, against C. pomonella larvae and found that the tested EPFs were less effective than azinphos-methyl according to the fruit damage of apples. However, there is no study regarding the isolation and pathogenicity determination of EPFs against C. pomonella in walnut fields even though this insect is the most important pest of walnut.
Hereby, the use of local isolates in biological control programs should be advised since they may have a reduced risk of significant impact on non-target organisms when compared to exotic isolates and may be adapted to the habitat and soil types where they are found. This may increase the chances of success in the control of target pests. In this concept, fungal isolates obtained from this study seem to be good candidates against walnut pests since they were isolated from walnut cultivated soils.

\section{Conclusions}

Fourteen EPF isolates were isolated and characterized from the soils of walnut fields. Eight selected fungi were tested against $C$. pomonella larvae under laboratory conditions and showed significant pathogenicity levels. Since EPFs are available in walnut fields, they could be beneficial for controlling C. pomonella in the walnut fields through conservation of such biological control agents.

\section{Acknowledgements \\ We would like to thank Dr. Frantisek Marec for providing C. pomonella eggs. This study was supported by Ahi Evran University Scientific Research Projects} Coordination Unit, project number MMF.A4.17.002.

\section{Funding}

\section{Availability of data and materials}

All fungal isolates identified in this study are public-accessible and were deposited at Microbiology Laboratory, Department of Genetic and Bioengineering at Ahi Evran University, Kırşehir, Turkey.

\section{Authors' contributions}

SG carried out a large part of the whole experiments. AS collected soil samples in the field and participated in fungal isolation, phylogenetic analysis, statistical analysis, and some of gene sequencing experiments. FMS carried out some of fungal isolation and morphological characterization experiments. ES participated in gene sequencing, phylogenetic analysis, statistical analysis, and writing of the whole manuscript. All authors read and approved the final manuscript. 
Ethics approval and consent to participate

Not applicable

\section{Competing interests}

The authors declare that they have no competing interests.

\section{Publisher's Note}

Springer Nature remains neutral with regard to jurisdictional claims in published maps and institutional affiliations.

\section{Author details}

${ }^{1}$ Ahi Evran University, Faculty of Engineering and Architecture, Genetic and Bioengineering, 40100 Kırşehir, Turkey. ${ }^{2}$ Department of Medical Microbiology, Ahi Evran University School of Medicine, 40100 Kırşehir, Turkey.

Received: 11 April 2018 Accepted: 24 May 2018

Published online: 12 June 2018

\section{References}

Abbajeh AR, Nchu F (2015) Isolation and pathogenicity of some South African Entomopathogenic fungi (Ascomycota) against eggs and larvae of Cydia pomonella(Lepidoptera: Tortricidae). Biocont Sci Technol 25(7):828-842

Abbott WS (1925) A method of computing the effectiveness of an insecticide. J Econ Entomol 18:265-267

Bischoff JF, Rehner SA, Humber RA (2009) A multilocus phylogeny of the Metarhizium a nisopliae lineage. Mycologia 101:512-530

Garcia-Gutierrez C, Gonzales-Maldonado MB, Medrano-Roldan H, ChairezHernandez I (2004) Evaluación de la cepa BbP1 de Beauveria bassiana, Mycotrol $^{\oplus}$, Meta-Sin ${ }^{\oplus}$ y azinfos-metilico contra Cydia pomonella L. (Lepidoptera: Tortricidae) en laboratorio y campo. Folia Entomol Mex 43:1-7

Gardner WA, McCoy CW (1992) Insecticides and herbicides. In: Finkelstein DB (ed) Biotechnology of filamentous fungi. Elsevier, Amsterdam, pp 335-359

Goettel MS, Eilenberg J, Glare T (2005) Entomopathogenic fungi and their role in regulation of insect populations. In: Gilbert LI, latrou K, Gill SS (eds) Comprehensive molecular insect science. Elsevier, Amsterdam, pp 361-405

Goettel MS, Inglis GD (1997) Fungi: hyphomycetes. In: Lacey LA (ed) Manual of techniques in insect pathology. Academic Press, San Diego, pp 213-249

Gout M, Guindon S, Gascuel O (2010) SeaView version 4: a multiplatform graphical user interface for sequence alignment and phylogenetic tree building. Mol Biol Evol 27(2):221-224

Guindon S, Dufayard JF, Lefort V, Anisimova M, Hordijk W, Gascuel O (2010) New algorithms and methods to estimate maximum-likelihood phylogenies: assessing the performance of PhyML 3.0. Syst Biol 59(3):307-321

Gulsar Banu J, Subahasan K, lyer R (2004) Occurrence and distribution of entomopathogenic nematodes in white grub endemic areas of Kerala. J Plant Crops 32:333-334

Hall TA (1990) BioEdit: a user-friendly biological sequence alignment editor and analysis program for Windows 95/98/NT. NucleicAcids Symposium 41:95-98

Humber R (1997) Fungi: Identification. In: Lacey LA (ed) Manual of techniques in insect pathology. Academic Press, San Diego, pp 153-185

Jackson TA, Alves SB, Pereira RM (2000) Success in biological control of soildwelling insects by pathogens and nematodes. In: Gurr G, Wratten S (eds) Biological control: measures of success. Springer, London, pp 271-296

Lacey LA, Grzywacz D, Shapiro-llan DI, Frutos R, Brownbridge M, Goettel MS (2015) Insect pathogens as biological control agents: back to the future. J Invertebr Pathol 132:1-41

Lacey LA, Unruh TR (2005) Biological control of codling moth (Cydia pomonella, Lepidoptera: Tortricidae) and its role in integrated pest management, with emphasis on entomopathogens. Vedalia 12(1):33-60

Lovett B, St. Leger RJ (2017) The insect pathogens. Microbiol Spectrum 5(2) FUNK-0001-2016

Mamay M, Yanık E (2013) Determination of population development and infestation rates of codling moth [Cydia pomonella (L.) (Lepidoptera: Tortricidae)] by using different sampling methods in Şanlıurfa province. J Agricult Sci 19:113-120

Meyling NV, Eilenberg J (2007) Ecology of the entomopathogenic fungi Beauveria bassianaand Metarhizium anisopliae in temperate agro-ecosystems: potential for conservation biological control. Biol Control 43(2):145-155

Mills N (2005) Selecting effective parasitoids for biological control introductions: codling moth as a case study. Biol Control 34(3):274-282
Mota-Sanches D, Wise JC, Poppen RV, Gut LJ, Hollingworth RM (2008) Resistance of codling moth, Cydia pomonella (L.) (Lepidoptera: Tortricidae), larvae in Michigan to insecticides with different modes of action and the impact on field residual activity. Pest Manag Sci 64:881-890

O'Donnell K, Cigelnik E (1997) Two divergent intragenomic rDNA ITS2 types within a monophyletic lineage of the fungus Fusarium are nonorthologous. Mol Phylogenet Evol 7:103-116

Perez-Gonzales VH, Guzman-Franco AW, Alatorre-Rosas R, Hernandez-Lopez J, Hernandez-Lopez A, Carrillo-Benitez MG, Baverstock J (2014) Specific diversity of the entomopathogenic fungi Beauveria and Metarhizium in Mexican agricultural soils. J Invertebr Pathol 119:54-61

Rehner SA, Minnis AM, Sung GH, Luangsa-ard JJ, Devotto L, Humber RA (2011) Phylogeny and systematics of the anamorphic, entomopathogenic genus Beauveria. Mycologia 103:1055-1073

Rehner SA, Posada F, Buckley EP, Infante F, Castillo A, Vega FE (2006) Phylogenetic origins of African and Neotropical Beauveriabassiana pathogens of the coffee berry borer, Hypothenemushampei. J Invertebr Pathol 93:11-21

Republic of Turkey, Ministry of Agriculture and Welfare (2010) The control of walnut pests and diseases. Turkey, Ankara

Sevim A, Demir I, Demirbağ Z (2010b) Molecular characterization and virulence of Beauveria spp. from the pine processionary moth, Thaumetopoea pityocampa (Lepidoptera: Thaumetopoeidae). Mycopathologia 170:269-277

Sevim A, Demir I, Höfte M, Humber RA, Demirbağ Z (2010a) Isolation and characterization of entomopathogenic fungi hazelnut-growing region of Turkey. Biocontrol 55:279-297

Sevim A, Hofte M, Demirbag Z (2012) Genetic variability of Beauveria bassiana and Metarhizium anisopliae var. anisopliaeisolates obtained from the Eastern Black Sea Region of Turkey. Turk J Biol 36:255-265

Solis-Soto A, Garcia-Gutierrez C, Gonzales-Maldonado MB, Medrano-Roldan H, Galan-Wong YLJ (2006) Toxicidad De blastosporas De Beauverıa Bassıana (Vuill) contra palomilla Del Manzano Cydia pomonella L. (Lepidoptera: Tortricidae). Folia Entomol Mex 45(2):195-200

Strasser H, Vey A, Butt TM (2010) Are there any risks in using entomopathogenic fungi for pest control, with particular reference to the bioactive metabolites of Metarhizium, Tolypocladium and Beauveria species? Biocontrol Sci Tech 10(6):717-735

Thompson JD, Higgins DG, Gibson TJ (1994) CLUSTAL W: improving the sensitivity of progressive multiple sequence alignment through sequence weighting, positions-specific gap penalties and weight matrix choice. Nucleic Acids Res 22:4673-4680

Zimmermann G, Huger AM, Kleespies RG (2013) Occurrence and prevalence of insect pathogens in populations of the codling moth, Cydia pomonella L.: a long-term diagnostic survey. Insects 4:425-446

\section{Submit your manuscript to a SpringerOpen ${ }^{\circ}$ journal and benefit from:}

- Convenient online submission

- Rigorous peer review

- Open access: articles freely available online

- High visibility within the field

Retaining the copyright to your article

Submit your next manuscript at $>$ springeropen.com 